\title{
Gender and Perceived Usefulness of e-HRM Technologies. A Case of the Bankers' Experience in Tanzania
}

\author{
Judith Namabira*, Hezbon Tenison Mtawa \\ Institute of Rural Development Planning, Dodoma, Tanzania
}

\begin{abstract}
This study investigates the impact of gender differences on the perceived usefulness of e-HRM technologies, using 158 observations from a survey conducted in one of the commercial banks in Tanzania. The descriptive statistics show that the e-HRM technologies in the bank have not been perceived as useful. With the T-Test, it has been found out that men perceive the e-HRM technologies more useful compared to women. The paper urges the promoters of e-HRM technologies in organizations to better understand the ways in which the use of such technologies can be enhanced to their employees, particularly women. The study proposes further research on e-HRM and gender, particularly on the impact of e-HRM technologies on spending, time saving, and errors.
\end{abstract}

Keywords: Adoption; Gender; Perceived usefulness; Perceived ease to use; e-HRM.

\section{Introduction}

Electronic, human resource management (eHRM) is a way of implementing human resources strategies, policies, and practices in organizations through a conscious and directed support of web-based technology channels, computer hardware and software, and electronic networking resources [1-4]. The intention behind e-HRM is to facilitate the function of human resource management with a composite of technologies and practices.

The adoption of e-HRM technologies, as is with other technologies, is greatly influenced by the factors of perceived ease of use and perceived usefulness [5-7]. While the perceived ease of use has to do with how one believes that the use of technology will be free from effort [5] or requires minimum effort [8], the perceived usefulness has to do with the degree to which a user of technology believes that using the technology is of use [5]. The perceived usefulness and ease of use are linked because, as Barhoumi [9] points out, the perceived ease of use can increase perceived usefulness and increase comprehension about technology adoption. Besides the perceived usefulness and the ease of use is also the perceived social pressure coming from individuals whose beliefs and opinions are important, including peers and people who are in social networks [10].

The concept of perceived usefulness was first defined by Davis [5] in the context of ICT as the degree to which a person believes that using a particular ICT would enhance his or her job performance. In this sense, perceived usefulness is linked to job performance and has been widely used so [8, 11-14]. It is in this same sense of performance that Lwoga [15] views perceived usefulness in the education realm, whereby perceived usefulness is the degree to which students believe that using technologies will improve their learning performances. Besides performance, perceived usefulness is linked to improving work: perceived usefulness as an individual belief that technology will make their work better [16].

Some research on gender and e-HRM adoption has been done. There has been some research on the key factors to influence the adoption of e-HRM technologies, among which 
gender is linked with the adoption attitudes [17]. Gender is also an area in which the findings of the Technological Acceptance Model (TAM) have been extended [18]. Sometimes it is surprising that gender is absent in studies where one would expect it to be. For instance, in a research about the factors that influence continuous intention to use E-HRM, using the Technology Acceptance Model and Cognitive Model for identifying significantly impacted areas of continuous intention to use E-HRM in a highly dynamic environment, one would expect to see gender relations; this is not the case [19]. Another example is a study by e-HRM experts about what transpired in the four decades of research in e-HRM [20]. These authors point out that the three factors that still seem to affect the adoption of e-HRM technologies are technology, the organization, and people; there is no mention of gender as an issue.

This study deals with the influence of gender on the perceived usefulness of e-technology. In a particular way, the study establishes how gender impacts on the perceived usefulness of eHRM technologies. The question for this paper is: are there significant differences between men and women bank employees' perceived usefulness in adopting e-HRM technologies? This question is premised on the finding by [21] that the demographic factors affect the individual's adoption of technological innovation and the Technology Acceptance Model (TAM), which postulates that the behavioral intention to adopt technology is a function of its perceived usefulness [22]. The study examines if a specific demographic factor, gender, affects the bankers' perceived usefulness of the e-HRM technologies at their workplace. The perceived usefulness is measured in terms of individual cost reduction, time-saving, and error reducing.
From a gender perspective, this study addresses the concern that studies of women and technology are neglected [23]. In a particular way, it adds on the inexistent literature regarding gender and the adoption of e-HRM technologies. The finding that there exists an e-HRM adoption gender technological divide is bound to inform the public policy goal of a globally equitable information society [24], particularly at workplaces; e-technologies are becoming increasingly vital to the management of human resources in public and private organizations, and hence the need to address the e-HRM technologies' adoption divide in gender, as well.

\section{Methodological Underpinnings}

The data being used in this paper derives from a quantitative survey conducted in 2019 in the three cities of Tanzania, one being the biggest, another one being the second biggest, and the last one being the fastest growing; the respondents were randomly selected from the branch categories of the mega, big, medium, and small branches. The bankers were targeted as the users of the e-HRM systems.

A questionnaire was designed in Google Forms and sent to the respondents by sharing a link via their WhatsApp accounts. Before the link was shared, a text was sent explaining the purpose of the study, assuring them of confidentiality of their responses and anonymity, and requesting their consent in order to participate in the study. Out of the 198-shared links, 162 were returned fully filled and submitted, yielding a response rate of $82 \%$. The profile of the respondents, as presented in Table 1 shows that most of the respondents had their Bachelor's degree (65\%), came from big branches (48\%), were adults of ages between 38 and $60(46 \%)$, were bankers by position (69\%), were experienced $(83 \%)$, and were male $(62 \%)$. 
Table 1. Respondents Profile

\begin{tabular}{|l|l|l|l|}
\hline Respondents & Gale & Frequency & Percent \\
\hline \multirow{3}{*}{ Agender } & Female & 97 & 61 \\
\hline \multirow{5}{*}{ Educational Level } & Below 35 years & 61 & 39 \\
\cline { 2 - 4 } & Above 35 years & 84 & 53 \\
\cline { 2 - 4 } & Secondary education & 74 & 47 \\
\cline { 2 - 4 } & Bachelor's degree & 8 & 5 \\
\cline { 2 - 4 } & Master's degree & 103 & 65 \\
\hline \multirow{5}{*}{ Pranch Size } & Small & 47 & 30 \\
\cline { 2 - 4 } & Medium & 31 & 19 \\
\cline { 2 - 4 } & Big & 54 & 33 \\
\hline \multirow{5}{*}{ Experience } & Support staff & 77 & 48 \\
\cline { 2 - 4 } & Banker & 8 & 5 \\
\cline { 2 - 4 } & Manager in bank & 112 & 69 \\
\cline { 2 - 4 } & Little experience (below 1 year) & 42 & 29 \\
\cline { 2 - 4 } & Moderate experience (between 1 \& 4 years) & 134 & 83 \\
\cline { 2 - 4 } & Very experienced (above 5 years) & 8 & 5 \\
\hline
\end{tabular}

Source: Researcher Survey (2019)

The collected data was about establishing the levels of agreement with the factors of adoption of e-HRM technologies and practices in the bank on a 5-point Likert scale whereby "1" stood for strongly disagree and " 5 " for strongly agree. The variables of interest from this data are enshrined in the following statements: (1) e-HRM technologies reduce my costs; (2) e-HRM technologies save my time; and (3) e-HRM technologies reduce my errors.

These statements were to be assessed by the respondents bearing in mind the e-HRM systems that have been used in the bank since the introduction of e-HRM technologies. The bank has employed three e-HRM systems since 2007 in order to dispense human resources services to the bank employees. Before the introduction of any e-HRM technologies, all HR activities were done manually. Tasks, such as leave applications, promotions, and transfers, to mention but a few, were done manually. With the introduction of e-HRM technologies, tasks began being automated. The first e-HRM system (E-TECH-1) was acquired in 2007 and was used till 2010; it was a stand-alone system on only one computer of the HR manager for the purposes of salary management. Another e-HRM system was adopted in 2010, and it is still in use till today; this system has several modules, namely: Payroll, Transition, Leave, and Loan request. Mid 2019, another e-HRM system was introduced, with more modules, namely: Performance and goals, Succession and development, Recruitment, and selection, Learning and development (learning management system), Compensation and Payroll, Employee Central (foundation for all the activities), and On-Boarding and Off-boarding.

The study tests the null hypothesis that gender does not matter in the perception of the usefulness of the e-HRM technologies; the alternative hypothesis is that gender matters in the perception of the usefulness of the e-HRM technologies. In describing the three variables that measure perceived usefulness (cheapness, time saving, and error reducing), an assessment is made about whether the factor is less useful or useful. Both the "strongly agree" and "agree" are assessed as "useful" (any mean score from 3.6 and above). "Completely disagree", "disagree", and "not sure" are assessed as less useful (any mean score below 3.6). The results are tabulated in Table 2. An independent-samples T-Test is used to determine whether the mean of the levels 
of perception of the usefulness of the e-HRM technologies (dependent variable) is the same or not for the two independent groups of males and females. The independent t-test determines whether the mean difference between the males and females is statistically significantly different to zero. Specifically, this is to test whether the perception of the usefulness of the e-HRM technologies changes according to gender. With a p-value of less than 0.05 , the null hypothesis is rejected, and the alternative hypothesis is accepted.

\section{Results}

\section{Assessing the Perceived Needs}

Table 2 summarizes the results regarding the assessment of the perceived usefulness.

Table 2. Assessment of the Perceived Usefulness

\begin{tabular}{|l|l|l|l|}
\hline Variable & Observation & Mean & Assessment \\
\hline e-HRM technologies reduce my costs & 158 & 3.322785 & Less useful \\
\hline e-HRM technologies save my time & 158 & 4.050633 & Useful \\
\hline e-HRM technologies reduce my errors & 158 & 2.841772 & Less useful \\
\hline General assessment & & $\mathbf{3 . 4 0 5 0 6 3 3}$ & Less useful \\
\hline
\end{tabular}

Source: Researcher Survey (2019)

The results in Table 2 show that the general perception assessment about the perceived usefulness of e-HRM technologies in the bank is that they are less useful (mean score <3.6). It is only the factor of e-HRM technologies that seems to be useful (mean score >3.6).

\subsection{Influence of gender on perceived usefulness}

Table 3 summarizes the results regarding the T-test performed on gender and the perceived usefulness of e-HRM technologies in the bank.

Table 3. Assessment of the Perceived Usefulness

\begin{tabular}{|l|l|l|l|}
\hline Factor & Gender & Means & P-value \\
\hline Reducing costs & Female & 2.540984 & \multirow{2}{*}{0.0000} \\
\cline { 2 - 3 } & Male & 3.814433 & \\
\hline \multirow{3}{*}{ Saving time } & Female & 3.803279 & \multirow{2}{*}{0.0095} \\
\cline { 2 - 3 } & Male & 4.206186 & \\
\hline \multirow{3}{*}{ Reducing errors } & Female & 2.344262 & \multirow{2}{*}{0.0000} \\
\cline { 2 - 3 } & Male & 3.154639 & \\
\hline
\end{tabular}

Source: Researcher Survey (2019)

The results in Table 3 show that gender has an impact on the perception of the usefulness of the e-HRM technologies. With the p-value $<0.05$, the null hypothesis that gender does not matter in the perception of the usefulness of the e-HRM technologies is rejected, and the alternative hypothesis that gender matters in the perception of the usefulness of the e-HRM technologies is accepted. In all the areas of perceived usefulness observed, the mean scores of the males are always high, compared to those of women: on reducing individual costs, for men
$3.8814433>2.540984$ for women; on saving individual time, for men 4.206186>3.803279 for women; on individual reducing errors, for men $3.154639>2.344262$ for women. These results imply that men, in general, perceive the usefulness of the e-HRM technologies more than women.

\section{Discussion}

The findings that male perceived more useful e-HRM technologies compared to women is consistent with some literature. For instance, in 
their extensive literature review regarding gender differences in technology usage, Goswami and Dutta [25] find out that in some contexts, such as the use of computers, email services, electronic data management systems, elearning applications, online stock trading, gender acts as an influencing factor as men are found to be more technologically adept compared to women and that females faced technical challenges and risk in using technology. Similarly, Venkatesh and Morris [26] found out that in the process of a new technology being introduced in school, male teachers gave more consideration to perceived usefulness than female teachers for making decisions regarding the use of new technology.

However, still, Goswami and Dutta [19] in their literature review, found out that the gender difference perception of usefulness is not being observed with respect to the use of social media, mobile or internet banking, e-commerce. Similarly, when Debrand and Johnson [27] examined gender differences concerning the perceived usefulness of e-mail and instant messaging for social communications, they found out that women perceived e-mail and instant messaging to be more useful, and they spent more time communicating with others via e-mail and instant messaging than men.

Hence, there are mixed results with respect to the influence of gender on the perceived usefulness of technologies, a situation that, in line with [28], suggests that the gender differences, or lack thereof, related to the perceived usefulness of technology may depend on the context in which the relevant technology is used, particularly the gender configurations of that community or organization.

\section{Conclusion}

From the gender perspective, the study affirms the gender gap in the perception of the usefulness of the e-HRM technologies. This implies that the women have not yet found eHRM technologies useful to them, compared to men, and consequently, the likelihood of poor adoption of such technologies. While it is true that technologies are gendered, it is also true that technologies shape gender relations. The promoters of e-HRM technologies in organizations need to better understand the way in which such technologies enhance the perception of their usefulness by their employees, particularly the women, who need to see these technologies more empowering than promoting or keeping the status quo of gender relations and their impact on lives. For this matter, further research on e-HRM and gender are needed, particularly on the impact of e-HRM technologies on spending, time-saving, and errors.

\section{Acknowledgements}

We would like to acknowledge the support of our employee, the Institute of Rural Development Planning, for its moral support and time in order to write this paper. We thank our colleagues from the Institute of Rural Development Planning (IRDP), Dodoma, who provided insights and expertise that greatly assisted the writing of this paper, although they may not agree with all of the interpretations and conclusions of this paper. We thank Prof. Adalbertus Kamanzi for his assistance with methodological comments that greatly improved this work.

\section{Conflict of Interest}

We, the authors, Judith Namabira and Hezbon Tenison Mtawa, hereby declare that the disclosed information is correct and that no other situation of real, potential, or apparent conflict of interest is known to us. We undertake to inform you of any change in these circumstances if any issue arises. 


\section{References}

[1] Ruel, H. J. M., Bondarouk, T., \& Looise, J. C., 2004, E-HRM: Innovation or irritation. An explorative empirical study in five large companies on web-based HRM, Management revue, 15(3), 364380 ,

http://www.management-

revue.org/papers/mrev_3_04_Ruel_Bondarouk_Looi se.pdf.

[2] Gopal, R., \& Shilpa, V., 2011, The implications of implementing electronic-human resource management (e-HRM) systems in companies, Journal of Information Systems and Communication, 2 (1), 10-29.

[3] Marler, J.H., \& Parry, E., 2016, Human resource management, strategic involvement and e-HRM technology, International Journal of Human Resource Management, 27 (19), 2233-2253, https://doi.org/10.1080/09585192.2015.1091980.

[4] Bondarouk, T., Ruël, H., \& van der Heijden, B., 2009, e-HRM effectiveness in a public sector organization: A multi-stakeholder perspective, International Journal of Human Resource Management, $20 \quad$ (3), 578-590, https://doi.org/10.1080/09585190802707359.

[5] Davis, F.D., 1989, Perceived usefulness, perceived ease of use, and user acceptance of information technology, MIS Quarterly, 13 (3), 319340.

[6] Agarwal, R. \& Prasad, J., 1998, The antecedents and consequents of user perceptions in information technology adoption, Decision Support Systems, 22 (1), 15-29.

[7] Rogers, E.M., 2003, Diffusion of Innovations, $5^{\text {th }}$ ed. New York: The Free Press.

[8] Huang, J., \& Martin-Taylor, M., 2012, Turnaround user acceptance in the context of HR selfservice technology adoption: an action research approach, The International Journal of Human Resource Management, 24 (3), 621-642.

[9] Barhoumi, C., 2016, User acceptance of the einformation service as information resource A new extension of the technology acceptance model, New Library World, 117 (9/10), 1-18.
[10] Igbaria, M., Parasuraman, S., \& Baroudi, J., 1996, A motivational model of microcomputer usage, Journal of Management Information Systems, 13 (1), 127-143.

[11] Adams, D.A., Nelson, R.R., \& Todd, P.A., 1992, Perceived Usefulness, Ease of Use, and Usage of Information Technology - A Replication, MIS Quarterly, 16 (2), 227-247.

[12] Taylor, S., \& Todd, P.A., 1995, Understanding Information Technology Usage - A Test of Competing Models, Information Systems Research, 6 (2), 144-176.

[13] Venkatesh, V., \& Davis, F.D, 2000, A theoretical extension of the Technology Acceptance Model: 21 / 21 Four longitudinal field studies, Management Science, 46 (2), 186-204.

[14] Venkatesh, V., Morris, M.G., Davis, G.B., \& Davis, F.D., 2003, User acceptance of information technology: Toward a unified view, MIS Quarterly, 27 (3), 425-478.

[15]Lwoga, T., 2012, Making Web 2.0 Technologies work for higher learning institutions in Africa. Campus, Wide Information Systems, 29 (2), 90-107. [16] Usoro, E. \& Majewski, G., 2014, A Model of Acceptance of Web 2.0 in Learning in Higher Education: a case study of two cultures, E-Learning and Digital Media, $11 \quad$ (6), www.wwwords.co.uk/ELEA.

[17] Myllymäki, D., 2021, Beyond the 'e-' in e-HRM: integrating a socio-material perspective, The International Journal of Human Resource Management, 32:12, 2563-2591, DOI: 10.1080/09585192.2021.1913624.

[18] Heikkila, J. 2013, Perspectives on e-HRM in the Multinational Setting, Vaasan Yliopisto.

[19] Noernam, T., Erlando, A., \& Riyanto, F.D., 2021, Factors Determining Intention to Continue Using E-HRM, Journal of Asian Finance, Economics, and Business, 8 (2), 1079-1089.

[20] Bondarouk, T., Parry, \& Furtmueller, E., 2017, Electronic HRM: four decades of research on adoption and consequences, The International Journal of Human Resource Management, 28 (1), 98131, DOI:

https://doi.org/10.1080/09585192.2016.1245672. 
[21]Quazi, A. \& Talukder, M., 2011, Demographic determinants of employees' perception and adoption of technological innovation, Journal of Computer Information Systems, 51 (3), 38-46.

[22]Davis, F., Bagozzi, R., \& Warshaw, P., 1989, User acceptance of computer technology: A comparison of two theoretical models, Management Science, 35 (8), 982-1003.

[23] Kuschel, K. \& Lepely, M., 2016, Copreneurial women in start-ups, Academia Revista Latinoamericana de Administración, 29 (2), 181 197. http://dx.doi.org/10.1108/ARLA-08-2015-0231. [24] United Nations, 2014, 'Empowering women entrepreneurs through information and communications technologies: a practical guide', UN Conference on Trade and Development, UNCTAD Current Studies on Science, Technology and Innovation, Vol. 9.

[25] Goswami, A., Dutta, S., 2016, Gender Differences in Technology Usage-A Literature
Review, Open Journal of Business and Management, 4. 51-59. http://www.scirp.org/journal/ojbm; http://dx.doi.org/10.4236/ojbm.2016.41006.

[26] Venkatesh, V., \& Morris, M. G., 2000, Why don't men ever stop to ask for directions? Gender, social influence, and their role in technology acceptance and usage behavior, MIS Quarterly, 24, 115-139. https://doi.org/10.2307/3250981

[27] Debrand, C.C., \& Johnson, J. J., 2008, Gender differences in email and instant messaging: A study of undergraduate business information systems students, Journal of Computer Information Systems, 48 (3), 20-30.

[28] Teo, T., Fan, X., \& Du. J., 2015, Technology acceptance among pre-service teachers: Does gender matter? Australasian Journal of Educational Technology, 31 (3), 235-251. 